\title{
Reliability of studies of iodine intake and recommendations for number of samples in groups and in individuals
}

\author{
Stig Andersen*, Jesper Karmisholt, Klaus M. Pedersen and Peter Laurberg \\ Department of Endocrinology and Medicine, Aalborg Hospital, Århus University Hosiptal, 9000 Aalborg, Denmark \\ (Received 13 April 2007 - Revised 6 August 2007 - Accepted 23 August 2007)
}

The iodine intake level in a population is determined in cross-sectional studies. Urinary iodine varies considerably and the reliability of studies of iodine nutrition and the number of samples needed is unsettled. We performed a longitudinal study of sixteen healthy men living in an area of mild to moderate iodine deficiency. Iodine and creatinine concentrations were measured in spot urine samples collected monthly for 13 months. From these data we calculated the number of urine samples needed to determine the iodine excretion level for crude urinary iodine and for $24 \mathrm{~h}$ iodine excretion estimated from age- and gender-specific creatinine excretions. We found that mean urinary iodine excretion varied from 30 to $87 \mu \mathrm{g} / \mathrm{l}$ (31 to $91 \mu \mathrm{g} / 24 \mathrm{~h}$ ). Sample iodine varied from 10 to $260 \mu \mathrm{g} / \mathrm{l}(20$ to $161 \mu \mathrm{g} / 24 \mathrm{~h})$. Crude urinary iodine varied more than estimated $24 \mathrm{~h}$ iodine excretion (population standard deviation 32 v. 26; individual standard deviation 29 v. 21; Bartlett's test, $P<0.01$ for both). The number of spot urine samples needed to estimate the iodine level in a population with $95 \%$ confidence within a precision range of $\pm 10 \%$ was about 125 (100 when using estimated $24 \mathrm{~h}$ iodine excretions), and within a precision range of $\pm 5 \%$ was about 500 ( 400 ). A precision range of $\pm 20 \%$ in an individual required twelve urine samples or more (seven when using estimated $24 \mathrm{~h}$ iodine excretions). In conclusion, estimating population iodine excretion requires 100-500 spot urine samples for each group or subgroup. Less than ten urine samples in an individual may be misleading.

Iodine excretion: Population study: Reliability: Variation: Sample size

Iodine deficiency may be a detrimental condition and iodine supplementation programmes are commonly implemented on a regional or national basis ${ }^{(1)}$. Excessive iodine intake may also have a negative effect ${ }^{(2,3)}$, and there is a need to describe population iodine intake more precisely.

The iodine intake of a population is commonly assessed by measuring iodine in urine in cross-sectional studies of selected cohorts $^{(3-8)}$. This provides information on the average iodine excretion and on the frequency of low iodine excretion values. However, urinary iodine excretion to a considerable extent reflects iodine intake over a short period of time prior to collection ${ }^{(9-11)}$, and the variation is huge ${ }^{(9-13)}$. This affects the reliability of estimates of population iodine intake level, and random variation may lead to low sample results in iodine replete individuals ${ }^{(13)}$. Thus, data are needed to determine the reliability of surveys with a certain number of urine samples and the number of samples needed to estimate the iodine excretion level. Also, data are needed to assess the reliability of subgroup analysis and the feasibility of using results of single values in individuals. The latter has been advocated $^{(12)}$ as iodine may vary less in individuals than in populations. However, data to support this, i.e. calculation of the number of urine samples necessary to estimate the individual iodine excretion, are lacking.

We aimed to estimate the number of urine samples needed to describe population and individual iodine excretion level, to describe the reliability of estimates of urinary iodine excretion in groups and in individuals, and to assess the precision of results of subgroup analysis.

\section{Subjects and methods}

Sixteen healthy Caucasian men, age $24-52$ years (median age 38 years) participated.

None took regular medication or iodine-containing vitamin or mineral preparations. None had undergone examinations with contrast media within 6 months prior to or during the study. The characteristics of the individual participants has been described previously ${ }^{(13)}$.

They lived in Jutland, Denmark, where the iodine intake is moderately low ${ }^{(14)}$. We made no restrictions to their daily or yearly routines and sampling procedures were designed to picture the procedures used in cross-sectional studies of urinary iodine excretion to describe the dispersion included in such studies. The study period of 1 year was chosen to include also seasonal differences in the estimate of variation ${ }^{(13)}$. Approval by the regional Ethics Committee was obtained prior to the commencement of the study.

Spot urine samples were collected monthly for 13 months. A morning (09.00-12.00 hours) spot urine sample was collected from each participant. All samples from a subject were analysed in random order in the same run. 
Assays

Urinary creatinine was measured by a kinetic Jaffé method ${ }^{(15)}$. Iodine was determined by the ceri/arsen method after alkaline ashing $^{(16)}$ as described previously ${ }^{(8,13,17)}$. Urinary iodine excretion was expressed in $\mu \mathrm{g} / \mathrm{l}$ and as an estimated $24 \mathrm{~h}$ urinary iodine excretion. This estimate was calculated as an age- and gender-corrected iodine:creatinine excretion ratio from creatinine excretions in age- and gender-matched group of Cauca$\operatorname{sians}^{(18,19)}$ as suggested previously ${ }^{(13,20,21)}$.

\section{Statistics and calculations}

The number of urine samples needed to assess the iodine excretion was calculated from the equation given in Fig. 1. This was developed to estimate the precision of a set-point, $D$, in biochemical variables ${ }^{(22)}$ and recommended for use when estimating the number of specimens required in biochemical measures ${ }^{(22)}$. The CI used $(Z)$ were 2.58 for $99 \%$, 2.33 for $98 \%, 1.96$ for $95 \%, 1.64$ for $90 \%, 1.28$ for $80 \%$, 1.04 for $70 \%, 0.84$ for $60 \%, 0.67$ for $50 \%$. The precision range $(D)$ used in the calculations varied from \pm 50 to $\pm 99 \%$, and this was the range within which the iodine excretion lies with the $\mathrm{CI}$ indicated by the $Z$ value chosen, as described in detail by Fraser \& Harris ${ }^{(22)}$. Using these Zstatistics may underestimate the sample size for small $n$ by up to $30 \%$ compared to using $t$-statistics but was chosen in order to comply with recommendations ${ }^{(22)}$. Mean within-individual variance was similar whether assessed as the mean variance among individuals or using ANOVA techniques. Within-subject $\mathrm{CV}$ was used for calculation of number of urine samples from an individual needed to assess the iodine excretion in an individual. The $\mathrm{CV} \%$ was the variance square root divided by the mean, as a percentage. Variances were compared by Bartlett's test for homogeneity of variances after ln-transformation that caused data to follow the normal distribution.

All data were processed and analysed using the Statistical Package for the Social Sciences version 10.0 (SPSS Inc.), Corel Quattro Pro X3 and a Texas Instruments TI-30X IIS calculator.

\section{Results}

Both urinary iodine concentrations and estimated $24 \mathrm{~h}$ iodine excretions are reported (Tables $1-3$ ) because some population studies include only crude iodine excretion while variation is lower when urinary iodine is corrected for dilution ${ }^{(13)}$.

Population mean urinary iodine excretion was $56.4 \mu \mathrm{g} / \mathrm{l}$ $(52.2 \mu \mathrm{g} / 24 \mathrm{~h})$. Sample urinary iodine ( $n$ 208) varied between

$$
n=(Z \times C V \% / D)^{2}
$$

Fig. 1. The components included in the calculation of the number of samples needed to be collected in order to describe a range for the iodine intake in a population $^{22}$. The number of urine samples needed to assess the iodine excretion ( $n$ ) was calculated by using the equation as recommended for use when estimating number of specimens required in biochemical measures ${ }^{22}$. The $\mathrm{Cl}$ used $(Z)$ were 2.58 for $99 \%, 2.33$ for $98 \%, 1.96$ for $95 \%, 1.64$ for $90 \%, 1.28$ for $80 \%, 1.04$ for $70 \%, 0.84$ for $60 \%, 0.67$ for $50 \%$. The precision range $(D)$ used in calculations varied from \pm 50 to $\pm 99 \%$, and this was the range within which the iodine excretion lies with the $\mathrm{Cl}$ indicated by the $Z$ value chosen, as described in detail by Fraser \& Harris ${ }^{22}$.
10 and $260 \mu \mathrm{g} / \mathrm{l}(20$ and $161 \mu \mathrm{g} / 24 \mathrm{~h}$ ), while individual mean urinary iodine excretion ( $n$ 16) varied from 30 to $87 \mu \mathrm{g} / \mathrm{l}$ (31 to $91 \mu \mathrm{g} / 24 \mathrm{~h}$ ) (Table 1$)$

Population standard deviation and average individual standard deviation were larger for crude urinary iodine than for estimated $24 \mathrm{~h}$ iodine excretion (32 v. 26 and $29 v .21)$ (Bartlett's test, $P<0 \cdot 01$ ), as was CV\% (56 v. $50 \%$ and $48 v$. $40 \%$ ) (Table 1).

Table 2 lists the number of urine samples necessary to be within a defined range of the actual iodine excretion level in a population with $95 \%$ confidence. Conversely, given a number of samples, the precision range for that survey can be read from Table 2 . Thus, in a study of 500 participants producing one spot urine sample each the precision range will be about $\pm 5 \%$. Hence, if the mean iodine excretion in a survey was $150 \mu \mathrm{g} / \mathrm{l}$, the population iodine excretion would be between 142 and $157 \mu \mathrm{g} / \mathrm{l}$.

Table 2 also illustrates the number of spot urine samples needed in an individual. Thus, ten spot urine samples from an individual gives the iodine excretion by approximately $\pm 25 \%$. Hence, if the mean iodine excretion of ten samples from an individual was $150 \mu \mathrm{g} / \mathrm{l}$, the true iodine excretion in that individual would be between 112 and $187 \mu \mathrm{g} / \mathrm{l}$ with $95 \%$ confidence. Collecting fifty samples in an individual narrows this down to around $\pm 10 \%$, i.e. $135-165 \mu \mathrm{g} / \mathrm{l}$ (Table 2).

Estimating $24 \mathrm{~h}$ urinary iodine excretion reduced population variance by $32.8 \%$, average individual variance by $45.3 \%$ and median individual variance by $12.2 \%$ compared to crude urinary iodine. Consequently, the number of urine samples needed to describe population iodine excretion was reduced by $22 \%$, and the number of urine samples needed in an individual was reduced by $16 \%$ (Table 2 ).

Table 3 illustrates how simultaneous changes in CI and precision range affects the number of samples needed. In the example, we chose to let CI and precision range vary in parallel. The number of urine samples needed to estimate the iodine intake level in a population with a confidence and precision of 98,95 and $90 \%$ was 4316,489 and 86 . This was reduced to 3383,383 and 67 when using estimated $24 \mathrm{~h}$ iodine excretions. Similar estimates in an individual with median variance required 1933, 219 and 38 samples, and 1620, 183 and 32 samples, respectively (Table 3).

Table 4 illustrates the effect of independent changes in CI and precision range. The number of urine samples needed in a population is dramatically more influenced by the precision range than by the $\mathrm{CI}$.

Fig. 2 shows how splitting up in subgroup analyses affects the precision of estimates of population iodine excretion. This is shown for different study population sizes and for both crude urinary iodine content (Fig. 2 (a)) and for estimated $24 \mathrm{~h}$ urinary iodine excretion (Fig. 2 (b)). Subgroup analysis influences mainly the precision of small studies.

\section{Discussion}

The number of participants in surveys of population iodine intake varies ${ }^{(3-8)}$. Consideration of the number of samples needed or the precision of the estimates of iodine excretion in such studies is hampered by the lack of data to support this. Thus, we evaluated the precision of estimates of iodine 
Table 1. Descriptives and mean urinary iodine excretion and variation in the individual participants and in the group

\begin{tabular}{|c|c|c|c|c|c|c|c|c|}
\hline \multirow[b]{2}{*}{ Participant } & \multirow[b]{2}{*}{ Age (years) } & \multirow[b]{2}{*}{ BMI $\left(\mathrm{kg} / \mathrm{m}^{2}\right)$} & \multicolumn{3}{|c|}{ lodine concentration $(\mu \mathrm{g} / \mathrm{l})^{\star}$} & \multicolumn{3}{|c|}{ lodine excretion $(\mu \mathrm{g} / 24 \mathrm{~h})^{\star} \dagger$} \\
\hline & & & Mean & Variance & CV\% & Mean & Variance & CV\% \\
\hline 1 & 35 & $27 \cdot 8$ & 53 & 464 & $40 \cdot 5$ & 46 & 1053 & 70.9 \\
\hline 2 & 28 & $21 \cdot 5$ & 37 & 218 & $39 \cdot 5$ & 31 & 97 & $32 \cdot 2$ \\
\hline 3 & 38 & $24 \cdot 7$ & 48 & 447 & $44 \cdot 3$ & 69 & 776 & $40 \cdot 2$ \\
\hline 4 & 38 & $26 \cdot 2$ & 54 & 380 & 35.9 & 50 & 389 & $39 \cdot 2$ \\
\hline 5 & 38 & $29 \cdot 0$ & 76 & 532 & $30 \cdot 5$ & 58 & 191 & $23 \cdot 7$ \\
\hline 6 & 53 & $26 \cdot 0$ & 66 & 601 & $37 \cdot 0$ & 47 & 317 & $38 \cdot 1$ \\
\hline 7 & 51 & $29 \cdot 4$ & 50 & 117 & $21 \cdot 8$ & 30 & 38 & $20 \cdot 3$ \\
\hline 8 & 53 & 21.4 & 55 & 2269 & 85.9 & 55 & 511 & 41.4 \\
\hline 9 & 31 & $22 \cdot 9$ & 52 & 359 & $36 \cdot 5$ & 48 & 192 & 28.9 \\
\hline 10 & 37 & $23 \cdot 9$ & 87 & 1113 & $38 \cdot 4$ & 91 & 721 & $29 \cdot 6$ \\
\hline 11 & 26 & $24 \cdot 5$ & 53 & 265 & $30 \cdot 5$ & 67 & 415 & $30 \cdot 2$ \\
\hline 12 & 53 & $26 \cdot 4$ & 48 & 302 & $36 \cdot 1$ & 55 & 411 & $36 \cdot 8$ \\
\hline 13 & 24 & $21 \cdot 3$ & 62 & 1089 & $53 \cdot 0$ & 44 & 188 & 31.2 \\
\hline 14 & 32 & $26 \cdot 2$ & 56 & 1683 & $73 \cdot 8$ & 64 & 654 & $40 \cdot 2$ \\
\hline 15 & 43 & 30.9 & 76 & 3168 & $74 \cdot 2$ & 49 & 1108 & $68 \cdot 3$ \\
\hline 16 & 48 & $24 \cdot 2$ & 30 & 60 & 25.9 & 32 & 88 & $29 \cdot 4$ \\
\hline Median & 38 & 25 & 54 & 456 & 38 & 50 & 400 & 34 \\
\hline Mean & 39 & 25 & 56 & $817 \ddagger$ & $48 d$ & 52 & $447 \ddagger$ & $40 \S$ \\
\hline Population & & & $56 \cdot 4$ & 1012 & $56 \cdot 4$ & $52 \cdot 2$ & 680 & $49 \cdot 9$ \\
\hline
\end{tabular}

* Based on thirteen samples in individual participants and on 208 samples in the population † Corrected for gender- and age-specific creatinine excretions ${ }^{18,19}$ as recommended ${ }^{8,13,20,21}$.

$\ddagger$ Calculated using ANOVA techniques gave similar results.

$\S$ Calculated as $\left(\Sigma \mathrm{CV} \%_{1-16}^{2}\right)^{1 / 2}$.

excretion with different survey population sizes using data previously collected and analysed ${ }^{(13)}$.

The number of urine samples needed to describe the iodine excretion was calculated from the equation used to describe the standard error of the mean ${ }^{(22)}$. The formula is quite straightforward after rearrangement to depict $n$ (Fig. 1) ${ }^{(22)}$. Two parameters need to be decided upon: the precision range and the CI. The precision range is interesting because it describes the range in which the true iodine excretion is likely to lie. As illustrated here, the precision range has a major impact on the number of urine samples needed. Narrowing this range down requires a steep increase in the number of urine samples. Adjusting the CI of the limits of the precision range has a smaller impact on $n$. Hence, while increasing the CI from 95 to $98 \%$ requires $41 \%$ more samples, narrowing the precision range similarly, i.e. from 5 to $2 \%$, causes a need for $525 \%$ more samples.

Increasing the number of urine samples from 100 to 1000 narrows the precision range from 11 to $3.5 \%$, while increasing from 1000 to 10000 narrows the precision range from 3.5 to $1.1 \%$, with $95 \%$ CI for all precision ranges. Thus, the first 900 samples reduces the precision range by $7.5 \%$ while an additional 9000 samples reduces this by only $2.4 \%$. Hence, if 10000 samples are feasible, a better use of resources may be to investigate a number of smaller groups representing different subgroups of the population rather than one large cohort. Whether such smaller groups should be separated in time, geography or social characteristics may depend on local factors. Yet, such design considerations likely allow for identification of population subgroups with insufficient or excessive iodine intake, and hence overall results more representative of the general population.

The optimal group size could be determined by $95 \%$ confidence, i.e. the combination of $95 \% \mathrm{CI}$ and a precision range of $\pm 5 \%$. As a rule of thumb, this requires spot urine samples from about 500 participants. Hence, if the average iodine excretion is $100 \mu \mathrm{g}$ in 500 samples from a population, then the true iodine excretion of that population will be between 95 and $105 \mu \mathrm{g}$ with $95 \%$ confidence. Given 100 spot urine samples, this will be between 90 and $110 \mu \mathrm{g}$, equal to widening the precision range to $\pm 10 \%$. This is parallel to the validity of subgroup analysis.

Dividing a survey population of 500 into two subgroups reduces the precision range of the estimate of iodine excretion level from \pm 5 to $\pm 7 \%$, i.e. widening the range of iodine excretion from $95-105$ to $93-107 \mu \mathrm{g} / \mathrm{l}$ with $95 \%$ confidence. A further subdivision into two groups reduces the precision range to around $\pm 10 \%, 90-110 \mu \mathrm{g} / \mathrm{l}$, and repeated subdivision reduces the precision range to $\pm 15 \%$, i.e. $85-115 \mu \mathrm{g} / \mathrm{l}$ in the example. This loss of precision can be compensated for by increasing the overall population size, to i.e. 5000, which narrows the overall precision range to below $\pm 2 \%$, i.e. $98-102 \mu \mathrm{g} / \mathrm{l}$ in the example, and $\pm 5 \%(95-105 \mu \mathrm{g} / \mathrm{l})$ in each of ten subgroups.

The basic information needed to do these calculations is knowledge of the variation in iodine excretion in the population. Urinary iodine varies markedly with both short-term variations ${ }^{(9,10)}$ and long-term variations ${ }^{(11,13)}$ due to dietary factors and dilution in addition to random variation ${ }^{(13)}$.

Diet is a major determinant of iodine excretion, including both constant factors such as tap water ${ }^{(23)}$, and more variable elements such as solid foods ${ }^{(8,24)}$. Thus, not only median iodine intake but also its variation increases in populations living on diets with variable use of iodine-containing chemicals in food ${ }^{(24)}$, and, thus the number of samples needed may be higher in such populations.

Variable fluid intake causes variation in urine volume, and thereby in the dilution of the urinary excretion of iodine from solid foods. This variation in urinary iodine content may be corrected for by using a ratio of sample iodine to creatinine. 
Table 2. Number of spot urine samples needed to be $95 \%$ confident of being within a specified range for crude urinary iodine concentration and for estimated $24 \mathrm{~h}$ urinary iodine excretion calculated from the variation in iodine excretion among healthy men undertaking daily lives

\begin{tabular}{|c|c|c|c|c|c|c|c|c|}
\hline \multirow[b]{4}{*}{ Precision range* } & \multicolumn{8}{|c|}{ Number of spot urines needed to sample for estimation of urinary iodine excretiont with a specified precision range } \\
\hline & \multicolumn{4}{|c|}{ Urinary iodine concentration $(\mu \mathrm{g} / \mathrm{l})$} & \multicolumn{4}{|c|}{ Estimated urinary iodine excretion $(\mu \mathrm{g} / 24 \mathrm{~h}) \ddagger$} \\
\hline & \multirow{2}{*}{$\begin{array}{c}\text { In a population§ } \\
n\end{array}$} & \multicolumn{3}{|c|}{ In an individual|| } & \multirow{2}{*}{$\begin{array}{c}\text { In a population§ } \\
n\end{array}$} & \multicolumn{3}{|c|}{ In an individual|| } \\
\hline & & Median variation & Lowest variation & Highest variation & & Median variation & Lowest variation & Highest variation \\
\hline $\pm 1 \%$ & 12218 & 5471 & 1827 & 28338 & 9575 & 4587 & 1.587 & 19307 \\
\hline $\pm 2 \%$ & 3054 & 1368 & 457 & 7084 & 2394 & 1147 & 397 & 4827 \\
\hline $\pm 5 \%$ & 489 & 219 & 73 & 1134 & 383 & 183 & 63 & 772 \\
\hline $\pm 10 \%$ & 122 & 55 & 18 & 283 & 96 & 46 & 16 & 193 \\
\hline $\pm 20 \%$ & 31 & 14 & 5 & 71 & 24 & 11 & 4 & 48 \\
\hline $\pm 30 \%$ & 14 & 6 & 2 & 31 & 11 & 5 & 2 & 21 \\
\hline $\pm 40 \%$ & 8 & 3 & 1 & 18 & 6 & 3 & 1 & 12 \\
\hline $\pm 50 \%$ & 5 & 2 & 1 & 11 & 4 & 2 & 1 & 8 \\
\hline
\end{tabular}

"Calculated with a $\mathrm{Cl}$ of $95 \%(Z=1.96)$

Calculated from $n=(Z \times C V / D)^{2}$, where $Z=1.96$ for $95 \% \mathrm{Cl}$ and $D$ is the precision range,

$\S$ Number of individuals needed to produce one urine sample was calculated based on the variation in the population

$\|$ Variation differs between individuals. Number of samples needed to sample in an individual are given for individuals with median, lowest and highest variation.

Table 3. Number of spot urine samples necessary to determine the iodine excretion level with a defined precision range and with parallel $\mathrm{Cl}$ for crude urinary iodine concentration and for estimated $24 \mathrm{~h}$ urinary iodine excretion calculated from the variation in iodine excretion among healthy men undertaking their daily lives

\begin{tabular}{|c|c|c|c|c|c|c|c|c|c|}
\hline \multirow[b]{4}{*}{$\mathrm{Cl}^{*}$} & \multirow[b]{4}{*}{ Precision range } & \multicolumn{8}{|c|}{ Number of spot urines needed to sample for estimation of urinary iodine excretiont with a defined precision range and $\mathrm{Cl}$} \\
\hline & & \multicolumn{4}{|c|}{ Urinary iodine concentration $(\mu \mathrm{g} / \mathrm{l})$} & \multicolumn{4}{|c|}{ Estimated urinary iodine excretion $(\mu \mathrm{g} / 24 \mathrm{~h}) \ddagger$} \\
\hline & & \multirow{2}{*}{$\begin{array}{c}\text { In a population§ } \\
n\end{array}$} & \multicolumn{3}{|c|}{ In an individual|| } & \multirow{2}{*}{$\begin{array}{c}\text { In a population§ } \\
n\end{array}$} & \multicolumn{3}{|c|}{ In an individual|| } \\
\hline & & & Median variation & Lowest Variation & Highest variation & & Median variation & Lowest variation & Highest variation \\
\hline $99 \%$ & $\pm 1 \%$ & 21170 & 9479 & 3166 & 49101 & 16590 & 7948 & 2749 & 33454 \\
\hline $98 \%$ & $\pm 2 \%$ & 4316 & 1933 & 645 & 10012 & 3383 & 1620 & 561 & 6821 \\
\hline $95 \%$ & $\pm 5 \%$ & 489 & 219 & 73 & 1134 & 383 & 183 & 63 & 772 \\
\hline $90 \%$ & $\pm 10 \%$ & 86 & 38 & 13 & 198 & 67 & 32 & 11 & 135 \\
\hline $80 \%$ & $\pm 20 \%$ & 13 & 6 & 2 & 30 & 10 & 5 & 2 & 21 \\
\hline $70 \%$ & $\pm 30 \%$ & 4 & 2 & 1 & 9 & 3 & 1 & 1 & 6 \\
\hline $60 \%$ & $\pm 40 \%$ & 1 & 1 & 1 & 3 & 1 & 1 & 1 & 2 \\
\hline $50 \%$ & $\pm 50 \%$ & 1 & 1 & 1 & 1 & 1 & 1 & 1 & 1 \\
\hline
\end{tabular}

${ }^{*} \mathrm{Cl}$ set to vary in parallel with the precision range.

‡Corrected for gender- and age-specific creatinine excretions ${ }^{18,19}$ as recommended ${ }^{8,13,20,21}$

$\S$ Number of individuals needed to produce one urine sample was calculated based on the variation in the population

|| Variation differs between individuals. Number of samples needed to sample in an individual are given for individuals with median, lowest and highest variation. 
Table 4. Number of participants producing one spot urine sample necessary to determine population iodine excretion level depending on precision range and $\mathrm{Cl}$ for urinary iodine excretion calculated from variation in crude urinary iodine concentration among healthy men undertaking their daily lives

\begin{tabular}{|c|c|c|c|c|c|c|c|c|}
\hline \multirow[b]{2}{*}{$\mathrm{Cl}^{*}$} & \multicolumn{8}{|c|}{ Precision range } \\
\hline & $\pm 1 \%$ & $\pm 2 \%$ & $\pm 5 \%$ & $\pm 10 \%$ & $\pm 20 \%$ & $\pm 30 \%$ & $\pm 40 \%$ & $\pm 50 \%$ \\
\hline $99 \%$ & 21170 & 5292 & 847 & 212 & 53 & 24 & 13 & 8 \\
\hline $98 \%$ & 17266 & 4316 & 691 & 173 & 43 & 19 & 11 & 7 \\
\hline $95 \%$ & 12218 & 3054 & 489 & 122 & 31 & 14 & 8 & 5 \\
\hline $90 \%$ & 8659 & 2165 & 346 & 87 & 22 & 10 & 5 & 3 \\
\hline $80 \%$ & 5211 & 1303 & 208 & 52 & 13 & 6 & 3 & 2 \\
\hline $70 \%$ & 3440 & 860 & 138 & 34 & 9 & 4 & 2 & 1 \\
\hline $60 \%$ & 2244 & 561 & 90 & 22 & 6 & 2 & 1 & 1 \\
\hline $50 \%$ & 1428 & 357 & 57 & 14 & 4 & 2 & 1 & 1 \\
\hline
\end{tabular}

${ }^{*}$ Calculated from $n=(Z \times C V / D)^{2}$, where $Z=\mathrm{Cl}(Z=2.58$ for $99 \%, 2.33$ for $98 \%, 1.96$ for $95 \%, 1.64$ for $90 \%, 1.28$ for $80 \%, 1.04$ for $70 \%, 0.84$ for $60 \%, 0.67$ for $50 \%)$ and $D$ is the precision range.
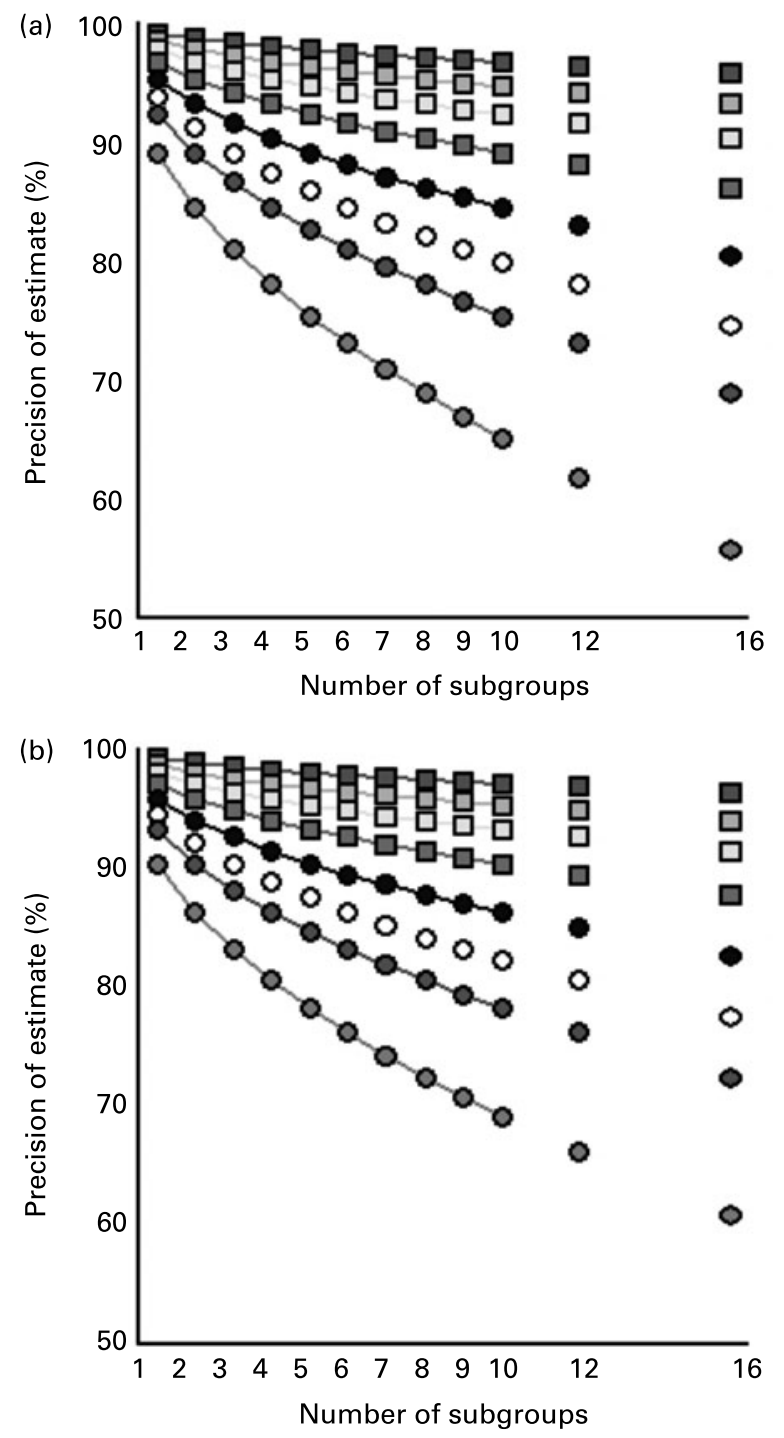

Fig. 2. Precision of estimates of population iodine excretion with increasing number of subgroups for different population sizes for crude urinary iodine $(\mathrm{a} ; \mu \mathrm{g} / \mathrm{l})$ and for estimated $24 \mathrm{~h}$ iodine excretion $(\mathrm{b} ; \mu \mathrm{g} / 24 \mathrm{~h})$. The equation in Fig. 1 was used, including the overall $\mathrm{CV} \%$ for the population (Table 1), with $Z=1.96$, i.e. $95 \%$ confidence of the precision range $D$ specified on the $y$-axis. $n=\square, 10000 ; \square, 4000 ; \square, 2000 ; \square, 1000 ; 0,500 ;$ O, 300; O, 200; O, 100.
The use of age- and gender-matched $24 \mathrm{~h}$ urinary creatinine values from the same or a similar population seems the more appropriate ${ }^{(20,21)}$. This reduces variation in iodine excretion by one-third compared to crude urinary iodine, and reduced the number of samples needed to describe population iodine excretion by about one-fifth.

The group included was relatively homogeneous. A gender difference in iodine excretion may add to the variation ${ }^{(25)}$, while old age may reduce this for dietary reasons. Thus, variation may be higher in the general population, and the present estimates should be considered as minimum requirements.

Data were collected prior to the initiation of the Danish iodine fortification programme ${ }^{(7)}$. Iodine fortification increased the average iodine intake ${ }^{(26)}$. This may increase variation also, depending on distribution and use of salt in the population. If so, the number of samples needed to monitor iodine fortification programmes will be higher than the present estimates, and data should be provided to clarify this.

The relevance of determining individual iodine excretion is debated. The thyroid gland has the capacity to store large amounts of iodine, unaffected by short-term low iodine intake. In addition, iodine excretion in the individual reflects the iodine intake over a short period of time prior to collection $^{(9,10)}$, and urinary iodine excretion varies considerably ${ }^{(13)}$. Thus, short-term estimation of individual iodine intake may likely be inaccurate ${ }^{(27)}$.

We used the $z$-statistics as recommended ${ }^{(22)}$. This, however, may underestimate sample size for small numbers of samples compared to $t$-statistics. Comparison of the two methods for estimating number of urine samples needed in the individual showed an underestimation up to $30 \%$. Hence, a precision range of $\pm 10 \%$ with $95 \%$ confidence required forty-six samples using $z$-statistics, while fifty-eight samples were needed when using $t$-statistics. Similarly, settling with $\pm 20 \%$ precision range required eleven samples with $z$-statistics compared to sixteen samples with $t$-statistics. This underestimation adds to the uncertainty related to estimating urinary iodine excretion in individuals.

In conclusion, the number of urine samples needed and the precision of estimates of iodine excretion with different survey population sizes in studies of iodine intake is now available. Five hundred spot urine samples describes population iodine excretion with about $\pm 5 \%$ precision. In an individual, more than ten urine samples are needed to avoid misleading evaluations. 


\section{References}

1. World Health Organization (2001) Assessment of Iodine Deficiency Disorders and Monitoring their Elimination. A Guide for Programme Managers. Geneva: WHO.

2. Laurberg P, Bulow Pedersen I, Knudsen N, Ovesen L \& Andersen S (2001) Environmental iodine intake affects the type of non-malignant thyroid disease. Thyroid 11, 457-469.

3. Teng W, Shan Z, Teng X, et al. (2006) Effects of iodine intake on thyroid function in China. N Engl J Med 354, 2783-2793.

4. Toteja GS, Singh P, Dhillon BS \& Saxena BN (2004) Iodine deficiency disorders in 15 districts of India. Indian J Pediatr 71, 25-28.

5. Hollowell JG, Staehling NW, Hannon WH, et al. (1998) Iodine nutrition in the United States. Trends and public health implications: iodine excretion data from National Health and Nutrition Examination Surveys I and III (1971-1974 and 1988-1994). J Clin Endocrinol Metab 83, 3401-3408.

6. Li M, Eastman CJ, Waite KV, et al. (2006) Are Australian children iodine deficient? Results of the Australian National Iodine Nutrition Study. Med J Aust 184, 165-169.

7. Laurberg P, Jørgensen T, Perrild H, Ovesen L, Knudsen N, Pedersen IB, Rasmussen LB, Carlé A \& Vejbjerg P (2006) The Danish investigation on iodine intake and thyroid disease, DanThyr: status and perspectives. Eur $J$ Endocrinol 155, 219-228.

8. Andersen S, Hvingel B, Kleinschmidt $\mathrm{K}$, Jørgensen $\mathrm{T}$ \& Laurberg P (2005) Changes in iodine excretion in 50-69-yold denizens of an Arctic society in transition and iodine excretion as a biomarker of the frequency of consumption of traditional Inuit foods. Am J Clin Nutr 81, 656-663.

9. Als C, Helbling A, Peter K, Haldimann M, Zimmerli B \& Gerber H (2000) Urinary iodine concentration follows a circadian rhythm: a study with 3023 spot urine samples in adults and children. J Clin Endocrinol Metab 85, 1367-1369.

10. Rasmussen LB, Ovesen L \& Christiansen E (1999) Day-to-day and within-day variation in urinary iodine excretion. Eur J Clin Nutr 53, 401-407.

11. Rasmussen LB, Ovesen L, Bulow I, Jorgensen T, Knudsen N, Laurberg P \& Pertild H (2002) Dietary iodine intake and urinary iodine excretion in a Danish population: effect of geography, supplements and food choice. Br J Nutr 87, 61-69.

12. Busnardo B, Nacamulli D, Zambonin L, Mian C, Piccolo M \& Girelli ME (2006) Restricted intraindividual urinary iodine concentration variability in nonfasting subjects. Eur J Clin Nutr 60, 421-425.

13. Andersen S, Pedersen KM, Pedersen IB \& Laurberg P (2001) Variations in urinary iodine excretion and thyroid function. A 1-year study in healthy men. Eur J Endocrinol 144, 461-465.

14. Laurberg P, Pedersen KM, Vestergaard H \& Sigurdsson G (1991) High incidence of multinodular toxic goitre in the elderly population in a low iodine intake area vs. high incidence of Graves' disease in the young in a high iodine intake area: comparative surveys of thyrotoxicosis epidemiology in East-Jutland Denmark and Iceland. J Intern Med 229, 415-420.

15. Bartels H, Bohmer M \& Heierli C (1972) Serum creatinine determination without protein precipitation. Clin Chim Acta 37, 193-197.

16. Wilson B \& van Zyl A (1967) The estimation of iodine in thyroidal amino acids by alkaline ashing. S Afr J Med Sci 32, $70-82$.

17. Laurberg P (1987) Thyroxine and 3,5,3'-triiodothyronine content of thyroglobulin in thyroid needle aspirates in hyperthyroidism and hypothyroidism. J Clin Endocrinol Metab 64, 969-974.

18. Kampmann J, Siersbæk-Nielsen K, Kristensen M \& Mølholm Hansen J (1974) Rapid evaluation of creatinine clearance. Acta Med Scand 196, 517-520.

19. Kesteloot H \& Joossens JV (1996) On the determinants of the creatinine clearance: a population study. J Human Hypertens 10, 245-249.

20. Jolin T \& Escobar del Rey F (1965) Evaluation of iodine/creatinine ratios of casual samples as indices of daily urinary iodine output during field studies. J Clin Endocrinol Metab 25, $540-542$

21. Knudsen N, Christiansen E, Brandt-Christensen M, Nygaard B \& Perrild H (2000) Age- and sex-adjusted iodine/creatinine ratio. A new standard in epidemiological surveys? Evaluation of three different estimates of iodine excretion based on casual urine samples and comparison to $24 \mathrm{~h}$ values. Eur $J$ Clin Nutr 54, 361-363.

22. Fraser CG \& Harris EK (1989) Generation and application of data on biological variation in clinical chemistry. Crit Rev Clin Lab Sci 27, 409-437.

23. Andersen S, Petersen SB \& Laurberg P (2002) Iodine in drinking water in Denmark is bound in humic substances. Eur $J$ Endocrinol 147, 663-670.

24. Pearce EN, Pino S, He X, Bazrafshan HR, Lee SL \& Braverman LE (2004) Sources of dietary iodine: bread, cows' milk, and infant formula in the Boston area. J Clin Endocrinol Metab 89, 3421-3424.

25. Andersen S, Pedersen KM, Iversen F, Terpling S, Gustenhoff P, Petersen SB \& Laurberg P (2007) Naturally occurring iodine in humic substances in drinking water in Denmark is bioavailable and determines population iodine intake. $\mathrm{Br} J$ Nutr 99, 319-325.

26. Vejbjerg P, Knudsen N, Perrild H, Carle A, Laurberg P, Pedersen IB, Rasmussen LB, Ovesen L \& Jorgensen T (2007) Effect of a mandatory iodization program on thyroid gland volume based on individuals' age, gender, and preceding severity of dietary iodine deficiency: a prospective, population-based study. J Clin Endocrinol Metab 92, 1397-1401.

27. Haddow JE, McClain MR, Palomaki GE, Hollowell BS \& Hollowell JG (2007) Urine iodine measurements, creatinine adjustment and thyroid deficiency in an adult United States population. J Clin Endocrinol Metab 92, 1019-1022. 